\title{
SPECIAL SECTION
}

Guest editors: Peter Schweitzer, Olga Povoroznyuk, Stephanie McCallum

\section{Introduction}

\section{Precarious Connections}

\section{On the Promise and Menace of Railroad Projects}

\author{
Peter Schweitzer and Olga Povoroznyuk
}

\begin{abstract}
This introduction attempts to situate railroads, which have rarely been the object of ethnographic attention, within current debates of anthropology and related disciplines. While mobility is certainly one dimension of human-railroad entanglements, the introduction calls to explore political, social, material, and affective lives of railroads in Europe and Asia as well. Often, connections provided by railroads are precarious at best: enveloped in state and local politics, they appear to some as promise and to others as menace. Planning, construction, decay, and reconstruction constitute the temporal and material life cycle of these infrastructures. Attending to particular ethnographic and historical contexts, the introduction aims to demonstrate how railroads, these potent symbols of modernity, continue to be good to think with.
\end{abstract}

\section{Keywords}

infrastructure, materiality, mobility, modernization, precarity, promises, railroads

When Greta Thunberg crisscrossed Europe in April of 2019 from her home in Stockholm to give speeches in London, Strasbourg, and Rome, she traveled exclusively by train, symbolizing the growing "no-fly movement," which has arisen in response to growing concerns about the impact of flying on climate change. This signals another twist in the way this means of transportation is being perceived.

Railroads, which have a relatively short history of less than two hundred years, have not always been associated with green or ecologically benign travel choices. On the contrary, the sight, smell, and sound of railroads in the nineteenth century signaled to many observers a satanic form of modernity and development. At the same time, enchantment with the sensation 
of speed has already been recorded from the earliest train passengers. ${ }^{1}$ The nineteenth-century replacement of animal power by the steam engine fueled by coal as the main energy source of overland travel led to an "industrialization of space and time," ${ }^{2}$ as well as more generally the emergence of a "fossil economy." ${ }^{3}$ This process of development and industrialization was also one of dispossession and imperial expansion. For example, the transcontinental railroads in the United States, once considered a shining exemplar of US entrepreneurial and engineering spirit, have come to be seen more critically in recent years, ${ }^{4}$ as a form of "railroad colonialism." ${ }^{5}$

While roads, the primary terrain for "automobility," have been in existence for much longer than railroads, car traffic only started in the twentieth century to emerge as a serious competitor to railroad transport of people and cargo. While almost every corner of the world received its share of railroad construction in the nineteenth century, the twentieth century saw the privatization and de facto abandonment of railroad transport in favor of cars, trucks, and buses in some countries (e.g., in Argentina under Carlos Menem). So, when the Canadian historian H. Vivian Nelles wrote an introduction to a republication of T. C. Keefer's Philosophy of Railroads in 1972, he started by lamenting that the railroad that had once "symbolized Canadian national achievement has been reduced to something akin to a public embarrassment." ${ }^{\prime}$ According to British writer Christian Wolmar, the "railway renaissance" started with the opening of the world's first high-speed line between Tokyo and Osaka in $1964 .{ }^{7}$ Almost sixty years later, this renaissance continues, now driven more by ecological concerns than by a fascination for high speed.

While we like to point to the shifting historical contexts in which railroads have been built and used, we are no experts in history, a discipline that has produced the bulk of social science and humanities literature on our subject matter. Even so, Wolmar's observation from more than ten years ago that "there is so little literature that focuses on the social history of the railways" ${ }^{\prime 8}$ still rings true. We are anthropologists who are interested in these often neglected social and cultural dimensions of this means of transportation. Likewise, while we focus on the "rail" aspect of what people in the United States call the "railroad," we will not completely neglect the issue of the "road," which can be seen as the underlying component of the transport infrastructure our special issue is interested in. Despite all (infra)structural similarities, road and railroad stand for two contrasting ideological qualities of passenger and cargo transport, namely private versus public transport, acknowledging that this clear-cut ideal type of distinction is rarely met in social reality. Thus, the railroad, which in many countries had been nationalized at one point or another, is symbolically more closely tied to the state than the car, although automobility would also be non-sustainable without state support. 


\section{Why a Special Issue?}

This special issue explores the ways the experience and very possibility of railroad mobility has been shaped by and mediated through political projects and shifting infrastructure. Railroads are often portrayed as a quintessential technology of industrial modernity. ${ }^{9}$ This issue will provide an overview of distinct modes of railroad projects, and of the particular social, material, and affective worlds afforded by them. What forms of mobility, relationality, and politics are mediated by railroads, vis-à-vis roads? How are different kinds of rail service associated with (post)socialist and/or neoliberal economies? Which imaginaries and affects are evoked by railroad construction and modernization plans under different political regimes? How do railroad lines reconfigure social and geographical spaces in remote and urban areas? These questions will be addressed in our collection of anthropological case studies coming from Asia and Europe.

While the "road" has been seen "as ethnography," ${ }^{10}$ treatments of the railroad have less often been conducted from an anthropological vantage point (but see the section below). We want to use the vibrant interdisciplinary platform that Transfers provides in order to examine the intersection between mobility, history, and culture, including the arrival and transformation of mobility in different locales. In this vein, our special issue seeks to foreground railroads as vectors of modernity and its discontents all-too-often disregarded by anthropological literature in favor of other (transportation) infrastructures. Here, the concept of a railroad encompasses both the combined passenger and cargo lines of the nineteenth and twentieth centuries, as well as the highspeed passenger trains of recent decades.

Thus, this issue focuses on human-railroad entanglements in specific ethnographic and historical contexts. We ask how railroads shape, and are shaped by, local and regional histories and culture, how railroads affect human mobility and sociality. In particular, this issue attends to railroad temporalities: the anticipation and allure of connection, the deferrals afforded by railroads yet-to-come, the nostalgia of railroads' past, the effervescence of social demands around public services, the cadence of train schedules and station sociality. The resurgence of railroad projects (if not always of actual railroad infrastructure) around the world, and the enduring affective allure of this form of transportation as a symbol of modernity, suggest that railroads continue to be a timely object of analysis.

As the articles in this issue illustrate, the connections provided by railroads are often precarious at best, on account of state and local politics, the promises and disenchantments of modernization plans, and protests against them, and the material and affective dimensions of construction, deterioration, and reconstruction. Simultaneously physical infrastructure, means of transportation, and large-scale development projects, railroads allow for a rich variety of 
analytical perspectives, including materiality approaches, infrastructure studies, and political economy. Finally, the passenger train, this vehicle for "moving with others,"11 provides unique opportunities for mobile ethnographies.

\section{What Do We Know So Far?}

In a recently published volume with the compelling title "The Promise of Infrastructure," material infrastructures are interpreted as dense social, aesthetic, and political formations that are critical both to experiences of everyday life at present and to expectations of the future and that "have long promised modernity, development, progress, and freedom to people all over the world." ${ }^{12}$ However, the infrastructures' promising circulation and distribution can turn into "precarious ensembles" that threaten breakdown and failure, as the rather recent examples of Fukushima Daiichi, Hurricanes Katrina and Sandy, among others, have shown. Moreover, the material and political lives of infrastructure projects often undermine narratives of progress, equality, and well-being, revealing or discriminating relations between people, things, and institutions that govern, build, or maintain them. Therefore, we should critically differentiate between what infrastructures promise and what infrastructures do. ${ }^{13}$

An article by anthropologists Penelope Harvey and Hannah Knox carries a similar message: infrastructures "enchant" with the promises of modernity. ${ }^{14}$ Drawing on their ethnographic study of roads in Peru, the authors trace the disruptive and destabilizing processes through which roads come to hold the promise of transformation. Roads enchant the public with respect to three specific promises: speed, political integration and economic connectivity, ${ }^{15}$ and appealing to the dreams of the majority, oriented toward a future, however, uncertain and unclear it is. ${ }^{16}$ In their follow-up book on the anthropology of roads in Peru, the same authors further elaborate on roads as political infrastructures that assemble experts and different kinds of publics in the process of their planning, engineering and construction. This rich ethnography of infrastructure and expertise illustrates that road construction is surrounded by stories of corruption and embezzlement and the sense of uncertainty and precarity. ${ }^{17}$

Mobility is another prominent promise of roads-an argument made in the special issue "Roads and Anthropology: Ethnographic Perspectives on Space, Time and (Im)Mobility." Roads "carry us back and forth between the sweeping narratives of globalization, and the specific, tangible materialities of particular times and places" and "elicit powerful temporal imaginaries, holding out the promise (or threat) of future connectivity." ${ }^{18}$ At the same time, roads can disconnect as effectively as they forge connection-an aspect deserving ethnographic attention in research on (im)mobility, differential speed, new 
landscapes, and networked infrastructures that can be instrumental for understanding exclusion of a growing population from a condition of mobility in correlation with freedom (to trade, to work, to travel, etc.). ${ }^{19}$

As we have argued above, in comparison with roads, railroads have only recently become the focus of attention of anthropology in general and anthropology of infrastructure in particular. As typologically close forms of infrastructure, railroads carry similar kinds of promises as roads. Likewise, they are fraught with danger to disconnect, demobilize, and undermine the well-being of the people, or, at least, of some groups, under (un)certain political and economic conditions. Thus, the connections that the railroads provide may come to be precarious, and the future promised by them, uncertain and gloomy. The historical accounts of railroads from different continents below illustrate the promise and menace of grand railroad projects that were designed and constructed to embody the power of the world empires but failed to realize their initial mission.

In their volume on "the railway and modernity," Matthew Beaumont and Michael Freeman trace the cultural history of technological ensembles engendered by railroads in Europe and in the United States in the nineteenth and the beginning of the twentieth centuries. The authors illustrate effects of railroadization on popular culture, passenger travel, and the imaginations of European and American citizens. The railroad boom opened up "unmapped spaces in countries and continents that had hitherto remained comparatively unmodernized" for travelers, ${ }^{20}$ stimulated mass employment, especially in the United States, ${ }^{21}$ and contributed to making reading a mass middle-class phenomenon. ${ }^{22}$ The train schedule not only became a passenger "cult," but also helped to "cement the nation" in the United States, as four main "standard zones" enforced by railroad companies replaced multiple "local zones." ${ }^{23}$ At the same time, railroad construction lead to overcrowding of urban areas and displacement of populations. Moreover, the trains were popularly associated with danger and death due to collisions, derailments, technological accidents, and concerns about travelers' safety. ${ }^{24}$ Yet, the authors conclude with the statement that railroad tracks remained a potent emblem of modernity in the twentieth century, despite playing a less transformative social role due to their increased embeddedness into the structures of the modern society.

Laura Bear's book rethinks the modernity of the railroads drawing on her case study from West Bengal, India. She reinterprets archives of a railroad company through the experiences of workers and their families. Her eloquent ethnography of the railroad colony at Kharagpur, stemming from practices of bureaucracy and accounts of workers, shows that the promised form of modernity the railroads were supposed to have brought with them to India has never existed. The railroad modernity in India has never eradicated the existing distinctions by community, caste, and race, but, in fact, generated a new "railroad caste" of Anglo-Indians or Jati that began to mark new forms of 
social distinction and political solidarity. ${ }^{25}$ Preferential recruitment of AngloIndians for upper subordinate positions on the railroads, regulation of their social space, and patterns of education, attempted to produce distinctions between the qualities of British civil society and Indian forms of sociality. As a result, this colonial administrative project has constructed a racial community that finds its social space in India within the confines of the Kharagpur colony. Bear's study shows how railroads can be conductors of marginalization and colonial and nationalist ethics grounded in transformed concepts of kinship and race.

Another book on India's railroads by Marian Aguiar explores multiple modernities symbolized and promised by the train as an icon of popular culture and mobility. The railroad depicted in short stories, poems, photographs and films, "became a kind of a moving theater that stages first a colonial, then a national, and finally a global identity." ${ }^{26}$ The author argues that the railroad symbolically correlated with modernity and movement much more than any previous form of transport. The predominant ideas about "liberating" modernity, however, implied Western (British) modernity with its practices and institutional forms established in Victorian England and its plans for development of commercial capitalism. While the rhetoric of colonial, secular nationalist, and post-colonial modernity have celebrated mobility as a means of emancipation, some people remained where they were before and others were displaced both geographically and socially. The railroads and associated mobility have become a place for a new segregation: racism has penetrated regulations of the use of platform and carriage space, and new marginalized groups (such as the railroad caste studied earlier by Bear) emerged in close alliance to the railroad and the workings of the British Empire. ${ }^{27}$

Richard White explores the role of railroads in nation-building and capitalist expansion, but brings us to another continent. ${ }^{28}$ In North America, railroads were the source of both national pride and great national discontent. But most importantly, they formed an international transport network, while being financed from the same sources and controlled by a relatively small interest group. In every country, the railroads were agents of the respective state: in the United States, for example, they helped to "pacify" Indian populations and to pour non-indigenous settlers into a vast region and to re-build the nation after the Civil War. The Canadian Pacific railroads were a product of Confederation, and in Mexico, they were an offspring of dictatorship. Yet, the modernity the transcontinental railroads brought everywhere was synonymous with the order imposed by impersonal large-scale organizations that invested in their construction, ripped off the profits, and left the nation-states to pay off the loans for them. The author concludes that American railroads were built ahead of demand, were good for entrepreneurs, but were harmful for the public. Manu Karuka's historical analysis of labor and racism on the Central Pacific Railroad, California, echoes some of the findings made by 
White, but makes even a stronger point that US railroads were conductors of colonialism and racism. These phenomena found their expression not only in relation to indigenous people, but also to Chinese workers who were participating in railroad construction. ${ }^{29}$

The historical account of three large-scale railroad projects below tell us yet another story of colonialism and modernity - that of the Russian and Soviet state. The famous Trans-Siberian Railroad (TransSib) became an iconic symbol of power of the Russian Empire and a path of colonization of Asian Russia in the late nineteenth and early twentieth centuries. The project was an "outgrowth of the historical urge of the Russian government to control its border territories through centralization and Russification." ${ }^{30}$ As the overall project was strongly motivated by politics and strategic concerns (oppression of secessionist sentiments), it did not result in immediate economic mobilization of the productive potential of Siberia. Yet, with the TransSib the state channeled the peasant resettlement movement, dispatched geological expeditions, improved water transport, and tried to stimulate local industry. ${ }^{31}$ The TransSib reveals parallels with follow-up railroad projects of the Soviet period motivated by political goals and dedicated to maintaining the state's power over its territory. ${ }^{32}$

The TurkSib-the Turkestan-Siberian Railroad-became one such landmark railroad project of the early Soviet period aimed at building socialism in Central Asia. ${ }^{33}$ The railroad was part of the Soviet campaign to industrialize and transform the country into the first socialist society and embodied the regime's commitment to "ethnic modernity." Matthew Payne, borrowing Sheila Fitzpatrick's concept "cultural revolution," shows how the TurkSib served the regime's "civilizing mission" (feeding and housing a workforce, building hospitals and schools, eradicating illiteracy, etc.), while generating victims and beneficiaries of the "liberation" policies (in the face of former subalterns) and bringing disorder to a society where old solidarities were delegitimatized and new ones were still uninformed. The two social groups on TurkSibengineers (migrants from the European part of the Union) and workers (Kazakhs and other ethnic minorities) - were each remolded by it into distinct industrial and social identities. A pattern of open and collective labor resistance, to the bosses and the regime's policies, was evident through large-scale strikes and riots, as not all builders subscribed to the official goal of Soviet nation-building. ${ }^{34}$

The Baikal-Amur Mainline (BAM), one of the longest northern railroads running parallel to the TransSib, became the last socialist megaproject built to bolster collective faith in the administrative system as well as to boost economic growth through exploitation of untapped resources of northern Siberia and the Far East. ${ }^{35}$ Like its many predecessors, it shared massive allocation of human and material resources, a highly inefficient utilization of them, and a general disregard for any impact on the environment. The socialist propa- 
ganda created the myth of the BAM filled with promises of ethnic and gender equality, solidarity, and economic prosperity. ${ }^{36} \mathrm{~A}$ critical revision of the BAM history deconstructed the official slogans of the project showing the cases of discrimination and marginalization of construction workers, economic unprofitability and adverse environmental impact of the construction project. ${ }^{37}$ Our anthropological research on the BAM, considering this historical perspective, argues that the transformative role of the project has reconfigured social and geographical spaces of northern Siberia by assimilating the indigenous population ${ }^{38}$ and forging a new group and identity of "BAM builders" in the process of the internal colonization of Siberia in the late Soviet period. ${ }^{39}$

A list of anthropological studies of railroads, in addition to the abovementioned book by Bear, should definitely include Edelman's eloquent ethnographic account about shunters' work in a contemporary railroad yard in Sweden ${ }^{40}$ Running a railroad requires more than physical infrastructures and technologies. First and foremost, it requires skilled labor by human workers. While social scientists and humanities scholars studying railroads from afar at times seemingly "forget" about the people keeping infrastructural systems running, anthropologists should know better than that. Still, detailed analyses of the lives and works of railroad workers are more the exception than the rule. An excellent example of this genre is Birgitta Edelman's Shunters at Work, which details the process of enskillment necessary to become a shunter (that is, a railroad worker assembling carriages into trains), and explains how technological and socioeconomic changes threaten a particular labor organization that constitutes a world for its participants. Having provided a vivid picture of how technology, organization of work, and social relations are intertwined, the author concludes that "connecting carriages also is a way of connecting people." ${ }^{41}$

Another prominent ethnography of railroads, written by Michael Fisch, focuses on the commuter train network in present-day urban Japan. ${ }^{42}$ Central to his study is the notion of the technosocial, which marks the convergence of the human and the technological, where the boundaries and structures of causal relations between the two cannot be clearly drawn or determined. The trains provide the primary means of transportation, making the tempo of the commuter network the pulse of the city. On a typical weekday morning in Tokyo, commuter trains on main lines are packed far above capacity, resulting in a train network that is perpetually on the verge of imminent collapse. This system works only by virtue of a complicated interaction between human and machine-the condition that embodies the technosocial. In his recently published book, the author develops his ethnography of commuter trains in Japan into "an anthropology of the machine." ${ }^{43}$ Using "technography" as an attempt to capture the "interplay of the human and the nonhuman," he asks: "How can we stay on the train and engage directly with the scene of technological mediation in ways that ... open new possibilities for thinking about modes 
of collectivity and technological becoming?" ${ }^{44}$ Critical to his understanding of relations between humans and machine is the notion of technicityreflection on techno-ethics demanding attention to specific kinds of relationality enabled by technology. Fisch argues that new technology comes to embody an infrastructural paradox: while it realizes a form of infrastructure able to withstand increasingly extreme environmental conditions caused by rampant capitalism, it simultaneously provides a novel schema of operation for its modes. Therefore, extreme infrastructures, such as commuter trains in urban Japan, come to embody new forms of extreme capitalism that exploits the dynamic qualities of collective life. ${ }^{45}$

Finally, in her essay about a golden spike, anthropologist Heather Swanson notes that "railroads ... put the world on a new track," ${ }^{46}$ emerging from and contributing to dreams of empires and desires of capitalist accumulation. Being products of socialist, capitalist, and neoliberal societies, they sparked vast ecological conversions, extinctions, and contamination and supported growing extraction of non-renewable resources. While trains are no more central to logistics and transportation in most parts of the world, the economic, political, environmental and imaginary patterns they had fostered remain firmly in place. Thus, the "golden spike" has the double meaning of (1) a ceremonial spike upon a launch or a completion of a railroad, and (2) a physical exemplar of a stratigraphic boundary in geological time. The author's call for placing a golden spike in the Anthropocene is a call for a "new train of thought" or a new narrative (about railroads and other human infrastructures) that weaves together pasts, presents, and futures in an attempt to stake out a new direction. ${ }^{47}$

We hope that this collection of articles provides such an attempt, by combining large-scale historical perspectives with detailed ethnographic attention to railroads as infrastructures that assemble different socialities, bridge distances and geographical locations, and (un)make particular temporalities. ${ }^{48}$ At the same time, attention to materiality of railroads as infrastructures paid in most of the articles reveals their centrality to sensory and affective ways in which we inhabit the world. We believe that the promissory and material dimensions of railroads are transformed in parallel: while new railroads make promises in the present about the future, old ones often symbolize ruins of an unrealized future and incomplete railroads often characterize experiences of neoliberal modernity.

\section{What Is to Come?}

While the articles to follow cover a wide range of case studies, they are somewhat interlinked by their Eurasian locations. Even more relevant, however, might be the fact that four of the six articles deal with postsocialist contexts. 
The two remaining articles—one about Italy and one about Japan-deal with not only rather different political and economic systems, but also much more high-tech versions of railroad technologies. What unites all of them, however, is the fact that they tell stories about precarious connections, be it in a material, symbolic, or temporal sense.

The article "(Dis)Connected Rail: Infrastructural Suspension and Phatic Politics in Romania" by Adrian Deoancă deals with a precarious connection in a very literal and material sense, namely with a suspended railroad line that had been running from the capital Bucharest to Giurgiu since 1869. In 2005, however, a bridge along the way crumbled into the river it used to span and all attempts since to rebuild the bridge, and to reopen the line, have been unsuccessful. The author uses the notion of "phatic politics" - derived from Roman Jakobson's use of the term "phatic" to point to channels of communicationto describe the various events, actions, and non-actions that have happened since. These communicative acts include feasibility studies, press releases, even "ghost trains," and engendered grassroots movements by citizens, which seem to be directed primarily at preventing the erasure of the issue from state and public attention. Still, while the now discontinued railroad line was built long before Romania became socialist, local narratives highlight the difference between socialist build-up and neoliberal disrepair. Thus, the suspension of a railroad line nurtures the suspension of hope and a nostalgia for the past.

Moving from postsocialist Romania to postsocialist Russia, "State of Uncertainty: Educating the First Railroaders in Central Sakha (Yakutiya)" by Sigrid Irene Wentzel looks at the future "human infrastructure" of a railroad-a sideline of the abovementioned BAM - that had not yet been running at the time of the author's fieldwork. At the center of attention here are not future passengers waiting for the train but students of a technical college-the railroad college-who are getting educated for jobs that do not exist yet. The state of uncertainty that these students find themselves in is not limited to a delayed start date of a railroad line but is connected to a bundle of unfulfilled promises in which first-generation industrial workers got enmeshed. We are reminded here again that neither working nor traveling on a railroad are natural skills but ones that need to be learned in the process of modernization. Unlike the Romanian case, where "suspension" led to a significant decrease in mobility, uncertainty along the Amur-Yakutsk Mainline just delayed the fulfillment of promises. Whether these promises will ever be fulfilled, and whether the aspirations of the railroad college students will come true, is uncertain at best.

"Connected or Traversed? Plans, Imaginaries and the Actual State of Railway Projects in Mongolia" by Maria-Katharina Lang and Baatarnaran Tsetsentsolmon also deals with the future, namely in the form of plans and imaginaries. The article is focused on Mongolia, another postsocialist country that hopes for profits emanating from China's aggressive transportation in- 
vestment plans and its geographic location between Russia and China. While Mongolia had a rocky history of becoming a railroad nation, today's obstacles are a mixture of geopolitical, financial, and infrastructural aspects serving as stumbling blocks on the way to a supposedly glorious future. In a way, we are dealing here with another instance of "phatic politics," although the possible repercussions of realized railroad projects-a country transected by infrastructures built for and by others-are rarely contemplated. While open protest against these plans is not reported by the authors, anecdotes about how nobody would be wondering if the president built a railroad to the moon are another way of dealing with an endless string of promises.

"The Cadences of Rails: Unscheduled Stops in Tōkyō's Spaces of Flow" by Robert J. Simpkins deals with an important but often overlooked dimension of railroad infrastructures, that is, railroad stations and their immediate surroundings. The main locations of the article are station passageways, constituting a kind of bridge between urban space and the railroad, which are characterized by the fluctuations and rhythms of train schedules. The human actors under consideration are musicians who have internalized the "cadences of rails" and their rhythmic changes to their advantage. The author references what Michael Fisch ${ }^{49}$ had called the strategy to "finesse the interval" in trying to understand how the musicians manage to prompt passersby to stop in a space not intended for breaks in the flow. Musicians and listeners build a connection by disrupting the flow, or better, by using the intervals in railroad schedules to build short-lived islands of attention, that is, precarious connections between the railroad and the city. While the railroad seems to determine the rhythm, the passengers seem to have domesticated its flow for their purposes.

"Railway Territorialities: Topology and Infrastructural Politics in Alpine Italy" by Mateusz Laszczkowski brings us to another form of railroad-related action, namely political protest and resistance against a new high-speed railroad in Valsusa, Italy. Interestingly, the resistance is not directed against railroads in general, not even against high-speed railroads in general (as one line already runs through the valley), but against a particular new project, namely the "New Lyon-Turin Line," which would double the existing connection. The movement against it, generally known as the No TAV movement, unites a broad spectrum of residents-from Catholic church-goers to anarchists-against an infrastructural development that is seen as threat and not as a promise. The author uses the notion of topology, as "the social and material processes through which space is imagined and produced, to explore the history and present of railway politics in Valsusa." In the end, the author makes a clear distinction "between connections that nurture and those that delete." The example of Valsusa complicates the understanding of high-speed railroads as the "good" alternative to harmful air travel, highlighting its locally destructive potential. 
"(Re)Constructing the Baikal-Amur Mainline: Continuity and Change of (Post)Socialist Infrastructure" by Olga Povoroznyuk brings us back to Russia and to the Baikal-Amur Mainline (BAM), dealing with its socialist past, and with its postsocialist present and promised futures. While the current railroad modernization project (BAM-2) is being implemented under completely different conditions than the original socialist mega-project, BAM-2 deliberately evokes memories and effects tied to the original BAM construction process, one of the last gigantic development projects of the Soviet Union, fueled by ideology and economic incentives. The reconstruction project not only makes use of the existing material infrastructure-after all, it needs to follow the rails laid 40+ years ago-but also engages discursive practices of the past to evoke both nostalgia and hitherto unfulfilled promises of the future. Thus, we might be dealing with a particular form of "path dependence" here, namely one in which railroad and state officials use traces of the past for their present and future political purposes. It seems that the residents of the BAM region live through re-occurring cycles of promise and dis-enchantment.

The response by Heather Anne Swanson, "Why Railroads Now? Anthropology of Infrastructure and Debates around 'Green' Transit," brings the strands of discussions around railroads together and rounds up this collection of articles. It raises the question of why railroads have been important in rethinking the issues of modernity and temporality, ruination and materiality, affect and state governance. Railroads not only remind scholars of the need to connect the ethnographic and the historical but also prompt new forms of comparative scholarship. Moreover, these infrastructure objects, and their socio-economic, political and environmental contexts, urge us to pursue more-than-human research in the dramatically transformed landscapes they leave behind.

Thus, the articles in this collection illustrate that the promises of modernity, embodied by railroads in different parts of the world, end up playing out differently for different actors in different situations. On the one hand, railroad construction may foster the colonizing ambitions of the state, benefit extraction companies and other private investors, and bring desired forms of mobility and connectivity to some groups eventually. On the other hand, the benefits of socio-economic development promised by railroads, as well as by other large industrial infrastructures, rarely reach the local communities that typically have to shoulder the costs of environmental degradation and, somewhat paradoxically, of isolation and immobility that may come with railroads. Anthropological perspectives on railroads help facilitate a more comprehensive analysis of these promises and menaces, of enchantment, disenchantment and resistance, of construction, ruination, and reconstruction associated with the social life cycles of the perennial allure of these infrastructure objects. 
Peter Schweitzer is Professor and Deputy Chair at the Department of Social and Cultural Anthropology of the University of Vienna and Professor Emeritus at the University of Alaska Fairbanks. His theoretical interests range from kinship and identity politics to human-environmental interactions, including the social lives of infrastructure and the community effects of global climate change; his regional focus areas include the circumpolar North and the former Soviet Union. In recent years, his attention has been focused on infrastructures and the built environment, as is evidenced by a newly awarded ERC Advanced Grant on Arctic transport infrastructures (INFRANORTH). Email: peter.schweitzer@univie.ac.at

Olga Povoroznyuk received her highest degree from the Institute of Ethnology and Anthropology, Russian Academy of Sciences in Moscow. Currently she is a Postdoctoral Researcher at the Department for Social and Cultural Anthropology, University of Vienna and a member of the Austrian Polar Research Institute. She has published a book on the postsocialist transformations of ways of life, culture, and identity among Evenki people based on her long-term field research in indigenous communities in East Siberia. Her recent peer-reviewed publications cover the topics of ethnicity, identity and indigeneity, mobility, infrastructure and development in the Russian North. Email: olga.povoroznyuk@univie.ac.at

\section{Notes}

Acknowledgements: This introduction is based on research conducted in the framework of the project "Configurations of Remoteness: Entanglements of Humans and Transportation Infrastructure in the Region of Baikal-Amur Mainline" (CoRe), funded by the Austrian Science Fund (FWF), P 27625 Einzelprojekte. During the final months, additional support came from "Building Arctic Futures: Transport Infrastructures and Sustainable Northern Communities" (INFRANORTH), a research project funded by the European Research Council (PROJECT-ID: 885646). This special issue is an outcome of two designated conference panels on "Revisiting Railroads: Sociality, Mobility and Infrastructure" that took place in 2018, at the biennial conference of the European Association of Social Anthropologists (EASA) in Stockholm and at the annual meeting of the American Anthropological Association (AAA) in San Jose, CA, respectively. Finally, we want to thank Mr. Michael Anranter, MA, from the University of Vienna who provided editorial assistance.

1. A. F. Garnett, Steel Wheels: The Evolution of the Railways and How they Excited Engineers, Architects, Artists and Writers (Waldenbury: Cannwood Press, 2005), 192.

2. Wolfgang Schivelbusch, Geschichte der Eisenbahnreise: Zur Industrialisierung von Raum und Zeit im 19. Jahrhundert [History of the Railway Journey: On the Indus- 
trialization of Space and Time in the Nineteenth Century] (1980; Frankfurt/Main: Fischer, 2000).

3. Andreas Malm, "The Origins of Fossil Capital: From Water to Steam in the British Cotton Industry," Historical Materialism 21, no. 1 (2013): 15-68.

4. For example, see Richard White, Railroaded: The Transcontinentals and the Making of Modern America (New York: W. W. Norton, 2011).

5. Manu Karuka, Empire's Tracks: Indigenous Nations, Chinese Workers, and the Transcontinental Railroad (Oakland: University of California Press, 2019).

6. H. V. Nelles, "Introduction," in Philosophy of Railroads, and other essays, by T.C. Keefer, ed. H.V . Nelles (Toronto: University of Toronto Press, 1972): vii-lxiii, here ix.

7. Christian Wolmar, Blood, Iron and Gold: How the Railways Transformed the World (London: Atlantic Books, 2009), 314.

8. Ibid., 331.

9. Stephanie McCallum, Derailed: Aging Railroad Infrastructure and Precarious Mobility in Buenos Aires (PhD dissertation, University of California Santa Cruz, 2018), 3, 22.

10. Dimitris Dalakoglou and Penelope Harvey, "Roads and Anthropology: Ethnographic Perspectives on Space, Time and (Im)Mobility," Mobilities 7, no. 4 (2012): 459-465.

11. David Bissell, "Moving with Others: The Sociality of the Railway Journey," in The Cultures of Alternative Mobilities-Routes Less Travelled, ed. Phillip Vannini (Farnham: Ashgate, 2009): 55-69.

12. Nikhil Anand, Akhil Gupta, and Hannah Appel, eds., The Promise of Infrastructure (Durham, NC: Duke University Press, 2018), 3.

13. Ibid., 3-4.

14. Penelope Harvey and Hannah Knox, “The Enchantments of Infrastructure," Mobilities 7, no. 4 (2012): 521-536.

15. Ibid., 521 .

16. Ibid., 523-524.

17. Penelope Harvey and Hannah Knox, Roads: An Anthropology of Infrastructure and Expertise (Ithaca, NY: Cornell University Press, 2015), 4-14.

18. Dalakoglou and Harvey, "Roads and Anthropology," 459-460.

19. Ibid., 460.

20. Matthew Beaumont and Michael Freeman, The Railway and Modernity: Time, Space, and the Machine Ensemble (Oxford: Peter Lang, 2007), 14.

21. Ibid., 18.

22. Ibid., 25.

23. Ibid., 19.

24. Ibid., 39.

25. Laura Bear, Lines of the Nation: Indian Railway Workers, Bureaucracy, and the Intimate Historical Self(New York: Columbia University Press, 2007), 3.

26. Marian Aguiar, Tracking Modernity: India's Railway and the Culture of Mobility (Minneapolis: University of Minnesota Press, 2011), xii.

27. Ibid., 18-22.

28. White, Railroaded. 
29. Manu Karuka, "Colonialism, Racism, and Labor on the Central Pacific Railroad," California History 96, no. 2 (2019): 99-104, here 100.

30. Steven G. Marks, Road to Power: The Trans-Siberian Railroad and the Colonization of Asian Russia, 1850-1917 (Ithaca, NY: Cornell University Press, 1991), 220.

31. Ibid., 222.

32. Ibid., 225.

33. Matthew J. Payne, Stalin's Railroad: Turksib and the Building of Socialism (Pittsburgh, PA: University of Pittsburgh Press, 2001).

34. Ibid., 5-7.

35. Christopher J. Ward, Brezhnev's Folly: The Building of BAM and Late Soviet Socialism. Pittsburgh, PA: University of Pittsburgh Press, 2009).

36. Christopher J. Ward, "Selling the 'Project of the Century': Perceptions of the Baikal-Amur Mainline Railway (BAM) in the Soviet Press, 1974-1984," Canadian Slavonic Papers 43, no. 1 (2001): 75-95.

37. Ward, Brezhnev's Folly.

38. Peter Schweitzer and Olga Povoroznyuk, "A Right to Remoteness? A Missing Bridge and Articulations of Indigeneity along an East Siberian Railroad," Social Anthropology 27, no. 2 (2019): 236-252.

39. Olga Povoroznyuk, "The Baikal-Amur Mainline: Memories and Emotions of a Socialist Construction Project," Sibirica 18, no. 1 (2019): 22-52.

40. Birgitta Edelman, Shunters at Work: Creating a World in a Railway Yard (Stockholm: Department of Social Anthropology, Stockholm University, 1997).

41. Ibid., 9.

42. Michael Fisch, "On the Train: An Anthropology of the Technosocial in Contemporary Japan” (PhD diss., Columbia University, 2009).

43. Michael Fisch, An Anthropology of the Machine: Tokyo's Commuter Train Network (Chicago: The University of Chicago Press, 2018).

44. Ibid., 12.

45. Ibid., 19-23

46. Heather Anne Swanson, "Placing a Golden Spike at the Golden Spike: Railroads in the Making of the Anthropocene," in Placing the Golden Spike: Landscapes of the Anthropocene, ed. Dehlia Hannah and Sara Krajewski (Milwaukee, WI: Institute of Visual Arts, University of Wisconsin-Milwaukee, 2015), 102-111, here 103.

47. Ibid., 5 .

48. Hannah Appel, Nikhil Anand, and Akhil Gupta, "Temporality, Politics, and the Promise of Infrastructure," in The Promise of Infrastructure, ed. Nikhil Anand, Akhil Gupta, and Hannah Appel (Durham, NC: Duke University Press, 2018), 1-38, here 14-15.

49. Fisch, An Anthropology of the Machine. 